\title{
A Decision-Making Support System on a Products Recovery Management Framework. A Fuzzy Approach
}

\author{
Isabel Fernández, ${ }^{*}$ Javier Puente, Nazario García and Alberto Gómez \\ Superior Polytechnical School of Engineering, Department of Bussiness Administration \\ University of Oviedo, Campus Viesques s/n, 33204 Gijón, Asturias, Spain
}

\begin{abstract}
The considerable amount of uncertainty involved in defining the factors that affect reverse logistics (RL) decision-making and the complex interrelationships between those factors make it rather difficult to decide what recovery policy a business should pursue. This article proposes a fuzzy system that helps in such decision-making and thereby mitigates these difficulties. The knowledge related to the decision is incorporated into the system by means of conditional rules, which serve to provide the ideal recovery policy for each particular case. The model proposed is applied to the analysis of a number of examples and proves to be a versatile tool that provides coherent results. These characteristics could be of critical importance especially in the point of entry into the RL pipeline and in the centralized return centres.
\end{abstract}

Key Words: fuzzy decision support system, reverse logistics, recovery options.

\section{Introduction}

Recent years have witnessed an ever-increasing interest in reverse logistics (RL). Yet despite a burgeoning of papers on the subject there is a lack of shared, standardized methodologies for decision-making in the field [1]. In this line the aims of this article are twofold: first, it supplies a new model based upon fuzzy methodology to include subjectivity and uncertainty, inherent features of the returns management, in the decision-making processes [2]. Incorporating a fuzzy system into this emerging discipline to help decisionmaking will thus provide a back-up for quantitative studies in a field where the qualitative studies abound as hallmarks of the initial stage of research. Second, establishing a fuzzy model for this decision-making may prove a valuable tool in daily RL practice as the model provides an efficient system for returns management that rationalizes processes, facilitates returns diagnosis, and limits the exception-driven effect so commonly confronted in the RL context, having, in consequence, a direct impact on the companies' time of response and thus on its profitability. These features make the model especially decisive for the so-called gatekeeping, the centralized returns centres within the RL pipeline and for high clock-speed industries [3,4] and high 'marginal value of time' products [5].

This article is organized as follows. The next section explains the inherent complexity of RL management

*Author to whom correspondence should be addressed.

E-mail: ifq@uniovi.es

Figures 2 and 3 appear in color online: http://cer.sagepub.com through the analysis of factors that affect the decisionmaking, their interrelationships and their relevance depending on the type of product. The construction of the fuzzy model is then described, and results are analyzed. The article ends with the conclusions to be drawn from the study.

\section{Some Considerations on $R L$ and the Main Factors Affecting RL Strategies}

For the purposes of this article, RL is defined as the efficient and effective management of any item (used or not, finished article or component, module, material or packaging) that is sent by one member of a supply chain (SC) to another upstream-member for the purpose of recovering added value or material or for proper disposal. RL thus encompasses three types of activity: waste management (incineration or landfill), service (re-use), and recovery of the product. The latter option divides into further options: repair, refurbishing, remanufacturing, cannibalization, and recycling, which are in ascending order according to the amount of disassembly required and in descending order according to the recovered value.

The question as to which of the above options is the right one for a returned item is far from being trivial [6]. Nor is it always easily answered [7]. To illustrate this idea note that not all products are equally suited for value recovery and not even every unit of the same product is equally suited. A number of researchers claim that the plethora of intertwining factors that come into 
play during decision-taking figures amongst the reasons explaining the lack of progress in defining a solid theoretical framework for optimum decision-taking in the field of recovery $[8,9]$ and the lag in daily praxis.

The literature coincides in assigning critical importance to two of these factors: the characteristics of the product and the customer (see for instance [49]). In the context of RL, these two factors encompass a wide range of sub-factors summarized in Figure 1 (for paper dimension limits). The nature of the returned item largely determines the recovery options. For example, categories of packing and packaging will be candidates for reuse (pallets), recycling (plastic and glass bottles, aluminium tins), or waste disposal. The range of options for commercial and industrial goods is wider, and choice will generally depend on different parameters.

One of the hallmarks of return flows is that they are low in volume (except certain sectors, where returns can be as high as $50 \%$ ). This feature hinders economies of scale, a key concern when return policies are being considered [10,11]. The volume of returns is in turn influenced by cultural features, the physical characteristics of the article (weight, dimensions, and the number of articles in circulation).

As far as the recovery cost is concerned, it should include the logistics cost of organizing, collecting, packaging, consolidating, and sending articles to their final destination, and the costs inherent to the processes required to transform the product. The latter will in turn depend on parameters like: the amount of disassembly that the chosen recovery option entails, the degree of complexity/sophistication of materials and manufacturing alike and the uncertainty about the condition of the returned article. The availability of a unit can often only be ascertained after the product has been disassembled. A unit may then be found to be useless, meaning that the costs of disassembly, which is often labor intensive and frequently requires qualified staff, cannot be recovered.

Regarding value, two facets need to be considered: the product's market value and the recovery value. Products' market value is highly influential in deciding recovery strategies as a high value equates positively with company commitment to recovery [12]. In respect to recovery value, recovering strategic components or high-value modules represents an obvious unexploited business opportunity to reduce overheads (cost of acquiring new materials, disposal costs, fines for nonfulfillment of legal obligations, etc). To sum up, the 'value to be recovered' figure should reflect a net value that takes into account all the monetary variables and opportunity costs.

The fifth sub-factor considered in this article is the useful life of a product. Generally, end-of-life products rarely provide opportunities for recovery and efforts should be better focused on products with longer useful life and therefore more recovery potential. Finally there is the need for a market for reprocessed products [13-16]. Even though Purohit [17] defends the proliferation of secondary markets for products linked to rapid technological change or where consumers get rid of the product before the end of its life, there is a wide selection of examples of recovery systems that have failed because there is no market for remanufactured products.

With relation to 'customer characteristics', aspects such as distance to customers, number of customer locations, and their geographical distribution have influence on the economic feasibility of certain recovery options $[18,8]$. The degree of availability and the knowledge that clients have about recovery programmes should also be taken into account [19]. The knowledge of a company about its customers should also be taken into account when recovery decision is taken [15,20]; a close relationship with the customer reduces the inherent uncertainty to the process of returns, facilitating and enhancing recovery options that would be unfeasible in other scenarios. A final point to be noted is that customers' negative perceptions of remanufactured products can generally affect the profitability of the operation, and thus influence the recovery decision [21]. Vietor [22] describes how the inclusion of used components in some Xerox products lowered customer predisposition to buy the products.

Finally, the intertwining nature of all the abovementioned factors should be noted, and therefore the importance of undertaking a detailed analysis of those links before taking a decision. To sum up, both the number of factors and variables involved in returnsrelated decision-making together with the interaction and influences they have on each other make analyzing the right recovery options for specific cases far from easy.

\section{A Fuzzy Decision Support System to Determine Ideal RL Strategies}

\subsection{Justification of the Fuzzy Methodology in RL Context}

An exhaustive analysis of all the above mentioned factors, the uncertainty associated to its evaluation and the knowledge about their interrelations constitute a reliable basis for creating the knowledge base which will allow a fuzzy system to infer the optimal recovery option. Uncertainty and subjectivity are two settings in which a fuzzy methodology is particularly well suited, as the system it generates can be more manageable, flexible and adaptable to a particular business setting [23].

Fuzzy approaches in the SC management literature can be found in a range of different ways: to estimate the operative cycle times in the SC [24], to select ideal partners [25], to study fuzzy demands, supplies and/or costs related to the right inventory management 


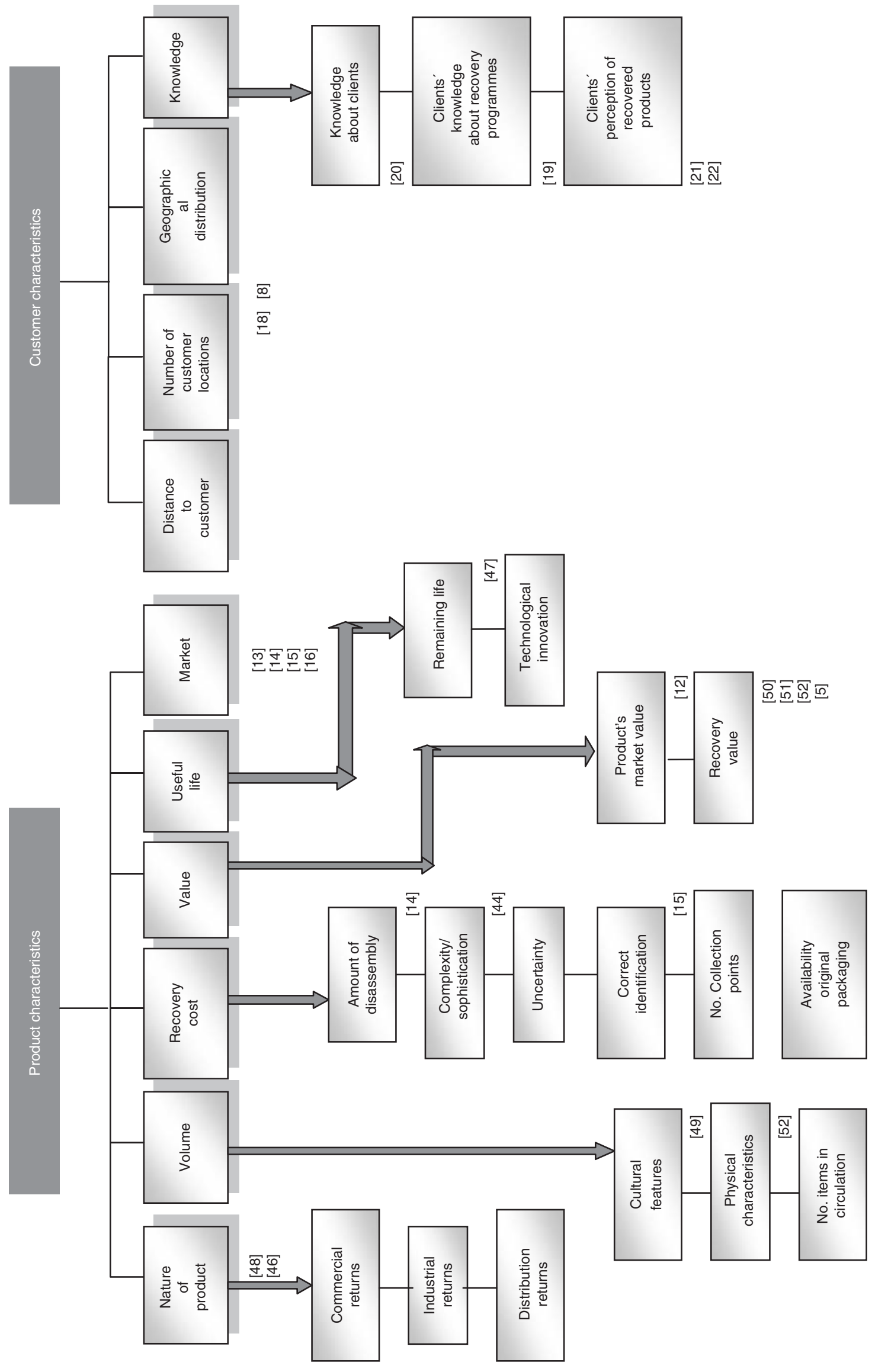


policies [26-30]. In spite of these works, there is a dearth of studies applying fuzzy methodologies to traditional SC [31], which becomes more acute in the RL field. This article attempts to fill a gap in the literature by generating a fuzzy decision system that renders the ideal RL strategy for any type of product in the light of certain key factors.

Fuzzy decision support systems are based on the theory of fuzzy sets [32], and allow an uncertainty component to be incorporated into models, making them more effective in terms of approximating to reality [33]. Linguistic variables can be used to handle qualitative or quantitative information, so that the content can be labeled taking words from common or natural language as values. This contrasts with numeric variables, which can only take numbers as values [34]. All decision problems require a knowledge base provided by an expert who is able to explain how the system works through a set of linguistic rules involving the system's input and output variables; the structure of the system's variables, that is, the form and range of the labels for each variable, must therefore be defined in fuzzy form. Fuzzy decision support systems of the Mamdani type depend on this logic to model systems in a process which has five stages [35]. The software used for the inference model design applied to the RL problem was MATLAB 6.5 - Toolbox 'Fuzzy' (v. 2,0). Mamdani Model - [36].

\subsection{Definition of Variables}

The consideration of a high number of input factors in the creation of a fuzzy model will provide greater discrimination potential when assigning the right output to the decision system, though it will also substantially increase the maximum number of decision rules to be generated, i.e., there are as many rules as combinations of the values of input variables [37]. In view of this, the fuzzy model proposed here includes the four input variables considered to be the easiest to evaluate in practical terms: product value, recovery value, useful life and level of sophistication. The output variable will be the optimal recovery policy.

'Product value (VALUE)', refers to the price the customer pays to acquire the article in the market. Four labels (very low, low, medium, and high) were created for this variable; examples of each one might be: (1) small household appliances, (2) large household appliances and office equipment, (3) means of transport, and (4) major works and structures (industrial warehouses, power plants). 'Recovery value (RESVALUE)' will be expressed as a percentage of a product's value, with three possible labels: low, medium, and high. Four labels were created for 'Product life (LIFE)' variable (low, medium, high and very high), so the longer a product's useful life is, the more incentives there are to choose the recovery option. Three labels (low, medium and high) have been created for 'Sophistication (SOPHISTIC)' variable, which refers to the amount of material in a product. Greater sophistication of materials generally results in more advanced recovery options; this is: more costly separation of the materials involved is required, higher staff costs, more qualified human resources etc. Finally, the fuzzy inference system generates a value that equates to one of six options relating to 'Recovery policy (POLICY)': five recovery options and one disposal option. Three labels have been used, with two options within each label. Thus, the 'low' label corresponds to the disposal and recycling options, the 'medium' label to refurbishing and repair, and the 'high' label to cannibalization and remanufacture. Whereas the 'low' label encompasses options where there is less recovery value (when disposal does not even figure as a recovery option; recycling only involves recovering materials), the other two alternatives indicate ever-higher recovered added value. The structure of all these variables is depicted in Figure 2.

\subsection{Definition of the Fuzzy Rule Base}

Once the structure of the variables of the system has been defined, knowledge relating to decision-making must then be incorporated into the model. To do this, the expert will use his/her experience to derive the 'if-then' rules that will determine the right recovery policy for each feasible combination of labels of the input variables. An example of a rule may be: if ((VALUE is med) \& (RESVALUE is high) \& (LIFE is low) \& (SOPHISTIC is med)), then (POLICY is low). In our study a few practitioners were asked to give insights about the rules. Some case studies from literature were also enlightening in the task of building the knowledge required for the system. A priori, the combinations of the labels assigned to the input variables $(3 \times 4 \times 3 \times 3)$ provided the experts with as many as 108 rules for assigning recovery policies.

Once the knowledge base has been defined (input and output variables and decision rules), the fuzzy inference process (Mamdani type in this article) is obtained for each entry vector of 'crisp' values. Figure 3 illustrates the decision system and the score given to each proposed recovery policy from any combination of values assigned to the four input variables. The tool can also represent the sensitivity of the proposed recovery policies for different scenarios according to the variations in any of the input variables. The surface maps obtained in this way are analyzed in the following section. 


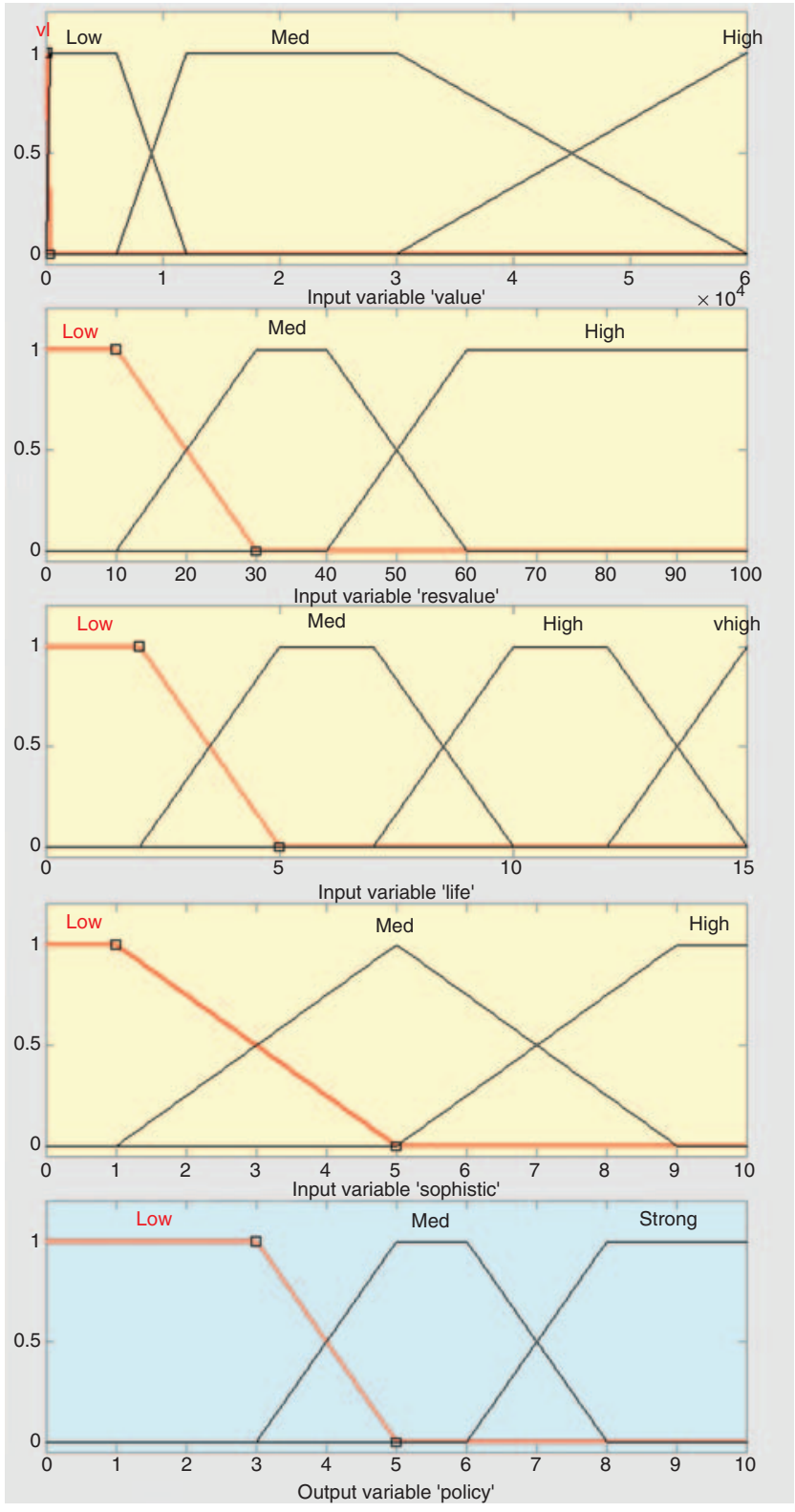

Figure 2. Structure of the model's input and output variables.

\section{Analysis and Discussion of the Results Provided by the Decision Support System}

This section contains an analysis of the decision system's output for some different combinations of input variables.

Figure 4 shows possible recovery policy decisions for products with a 'low' product value and 'average' sophistication for any value of the other two input variables: useful life and recovery value. The surface map highlights how even the items in this low product value category may be candidates for advanced recovery options provided they still have long periods of useful life and reasonable rescue value. On the other hand, products with a shorter life cycle are mostly consigned to disposal/recycling by the model.

When only the recovery value axis is considered, the surface map highlights how higher recovery value levels would point towards such policies as remanufacturing; in contrast, low values of this variable would indicate less advanced alternatives, such as disposal or recycling.

Figure 5 illustrates three possible recovery policy output decisions for products with a 'low' value and 'low'-'average'-'high' useful life respectively for any values of the other two input variables: sophistication and recovery value.

These three graphs show the sensitivity of the policies recommended by the fuzzy decision system to valuate changes in the variables. The upper chart, in particular, shows how the best policy for a product with a short useful life is one of repair or refurbishing only when the recovery value and product sophistication are low.

The product's life has been increased from 2-8 years in the chart in the middle, while the other values remaining unaltered. It is noteworthy that the policy of remanufacturing is recommended for high recovery value combined with low sophistication. Such a decision shift is explained by the greater time margins available for a company during which a more complex recovery process and dispatch-to-market procedure can be implemented. As sophistication levels increase and/or recovery value diminishes, the recommended options shift towards repair/refurbishment; for more extreme values the shift is towards recycling or mere disposal. Finally, the chart at the bottom illustrates the case of an item with a useful lifespan of 14 years, where the remanufacturing option is more adequate for a broader range of situations. Indeed this option is valid not only in the most favorable cases of low sophistication and recovery value of above $40 \%$ but also for other alternatives as well, such as high sophistication levels and lower recovery value.

Charts in Figure 6 respectively show the recovery policies to be pursued for products with 'average' sophistication and 'low'-'very low' values for any of the other two input variables: useful life and recovery value.

The remanufacturing option recommended in the above figure for a higher value product with a long useful life and high recovery value is not worthwhile if the product has a low market value. In this particular case, the higher costs that remanufacturing entails compared to the simpler option of recovery and the longer time required to remanufacture fail to justify 
choosing this option over other options such as repair, for example.

All the above graphs highlight both the userfriendliness and the consistency of the decision system that this article proposes. They demonstrate that it is an extremely useful tool to supply answers for different scenarios, and show how the recovery option evolves in line with changing input variables. Moreover, products that are well known and described in the literature have also validated the tool (Table 1). The ideal option for cell phones at the end of their useful life, for example, is usually disposal or recycling. When the system described here was tested on this type of product, four input values were used, as follows: VALUE = 'very low', RESVALUE = 'low', LIFE = 'low', and SOPHISTIC $=$ 'medium.' The system gives a value that equates to a 'low' output policy, which is equivalent to assigning a policy of disposal or recycling to this type of product. Figure 3 illustrates the inference process for this decision.

A further example will be considered to state the sensitivity of the proposed model when changes affect input variables. In this new example, two additional inference processes for a photocopier machine will be described. This product is the epitome of a 'low' value product with an 'average' sophistication. So, in case the machine were at the end of its useful life (with low recovery value), model's input data might be: $\quad[\mathrm{VALUE}=1000, \quad \mathrm{RESVALUE}=15, \quad \mathrm{LIFE}=2$, and SOPHISTIC $=5$ ]. Under these conditions the system would return a value $[\mathrm{POLICY}=2.12$ ], related to the disposal or recycling options. However, if the machine were at the beginning of its useful life (with a higher recovery value), input data become: $[$ VALUE $=1000$, RESVALUE $=60, \quad$ LIFE $=10$, and SOPHISTIC $=5$ ]. In this case the returned value [POLICY $=8.47$ ] is now related to the cannibalization or remanufacturing options. In both cases, the policy recommended by the system matches those described in literature.

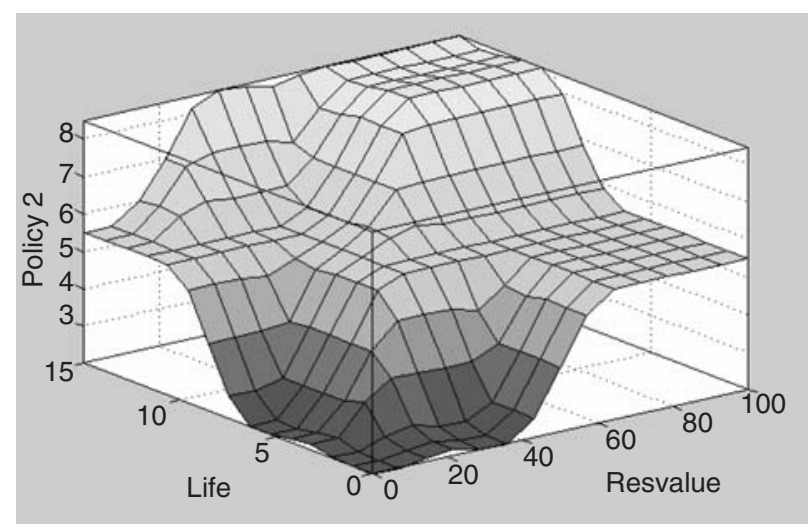

Figure 4. Evolution of POLICY in relation to LIFE and RESVALUE (when VALUE = 'low'; SOPHISTIC $=$ 'Med'.)

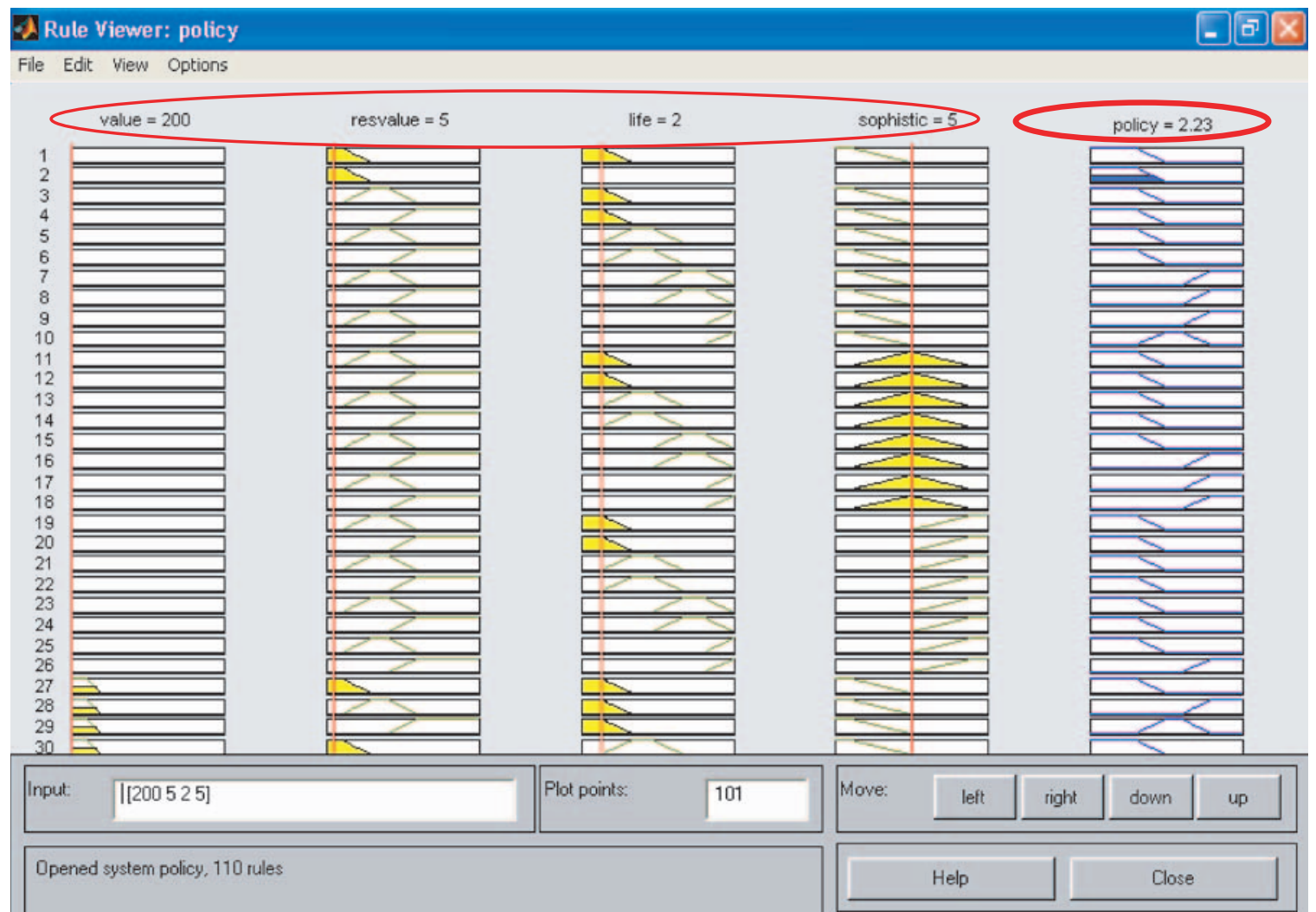

Figure 3. Inference viewer. The policy assigned to each input value vector. 


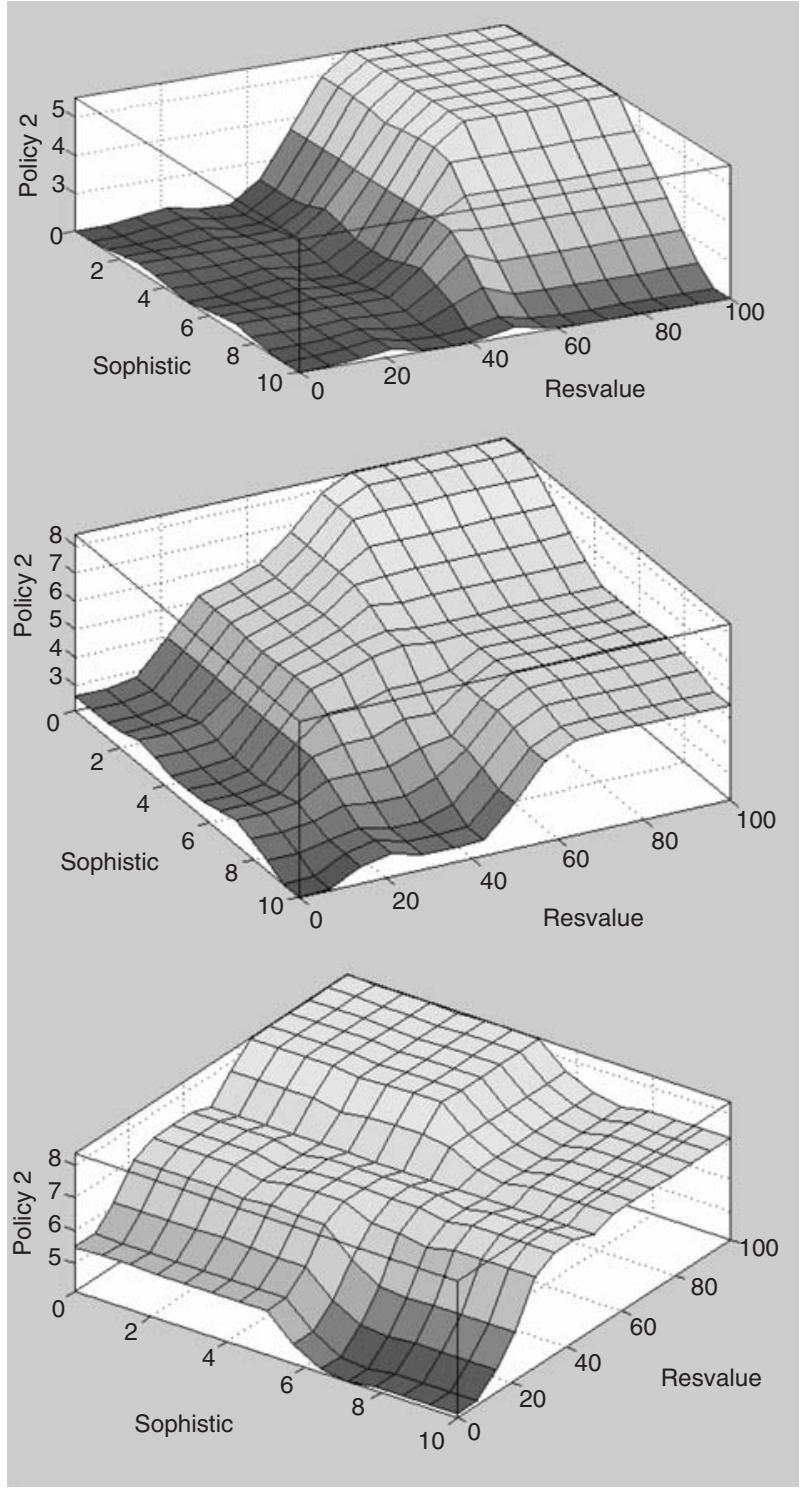

Figure 5. Evolution of POLICY in relation to SOPHISTIC, and RESVALUE (Top: when VALUE ='low'; LIFE ='low') (Middle: when VALUE ='low'; LIFE ='Medium') (Bottom: when VALUE $=$ 'low'; LIFE $=$ 'very high').

\section{Conclusions and Suggestions for Further Research}

Returns management is still considered by many companies to be one of the down sides of being in business and as a drain on management resources. This view may be the result of the lack of procedures and processes to aid that management. In turn, this might be compounded by the high degree of complexity and uncertainty inherent to the field of returns. However, both factors make the discipline the ideal field for the application of a fuzzy methodology, which serves to simplify returns management considerably. Two points in the RL pipeline may greatly benefit from speeding up this type of tasks: the gatekeeping point and the centralized returns centres. On the other hand, if decreasing processing times is important for any kind of product, it becomes decisive for high clock-speed industries and high 'marginal value of time' products. Results show the consistency and adequacy of the decision system built to account for real decisions to assign a given recovery policy. The system offers a coherent, dynamic diagnosis that shows how policy might change as values of the input variables also change.

Some of the major advantages of applying the fuzzy system in practice may be: a reduction in the inventory levels of returned products, a reduction in decision times, a reduction in flow congestion of returned products, shorter handling times in an activity that is traditionally labor-intensive, or fewer risks of degradation and ensuing loss of product value, among others. Furthermore, the ease with which the system can be slotted into a business management system is widely acknowledged, since MATLAB and its 'fuzzy' toolbox, which is a scientific, versatile and commercially available tool, are supported within WINDOWS environment.

Further research could include other factors that affect the final decision to different extents:

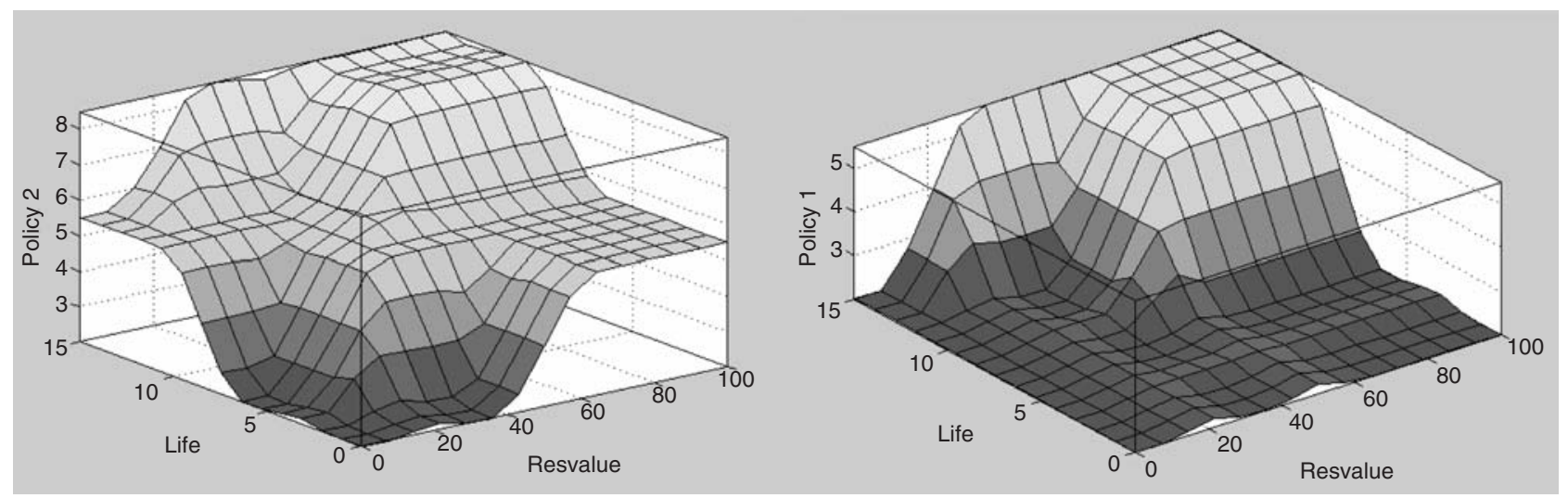

Figure 6. Evolution of POLICY with relation to LIFE and RESVALUE (Left: VALUE $=$ 'Iow' \& SOPHISTIC $=$ 'medium') (Right: VALUE $=$ 'very low' \& SOPHISTIC = 'medium'). 
Table 1. Recovery policies suggested by different researchers for different products.

\begin{tabular}{|c|c|c|}
\hline Product & $\begin{array}{l}\text { Usual recovery } \\
\text { policy (as in } \\
\text { the literature) }\end{array}$ & Source \\
\hline Cell phones & $\begin{array}{l}\text { - Repair } \\
\text { - Refurbish } \\
\text { - Cannibalization } \\
\text { - Recycling }\end{array}$ & $\begin{array}{l}\text { G.A. Kirkman, Greener Solutions Ltd., London, UK, personal communication, 2003; } \\
\text { Environmental Statement 2001, Shields Environmental Ltd., Essex, UK, April } 2002 . \\
\text { Nokia. http://www.nokia.co.uk, accessed } 2005\end{array}$ \\
\hline PC & $\begin{array}{l}\text { - Repair } \\
\text { - Remanufacturing } \\
\text { - Recycling }\end{array}$ & {$[38] \quad[39] \quad[40] \quad[41]$} \\
\hline Single use cameras & $\begin{array}{l}\text { - Reuse } \\
\text { - Recycling/ } \\
\text { Disposal }\end{array}$ & $\begin{array}{l}\text { Kodak, 'A Tale of Environmental Stewardship: the Single-Use Camera,' <www.kodak.com/ } \\
\text { US/en/corp/environment/performance/recycling/suc.shtm>, accessed } 2005 \text {. }\end{array}$ \\
\hline Toner cartridge & - Reuse & [42] \\
\hline Photocopier & $\begin{array}{l}\text { - Repair } \\
\text { - Refurbishing/ } \\
\text { remanufacture }\end{array}$ & $\begin{array}{l}\text { Environment, Health and Safety Progress Report 2002, Xerox Corporation, New York, } \\
\text { November 2002. [43] }\end{array}$ \\
\hline Car & $\begin{array}{l}\text { - Cannibalization } \\
\text { - Remanufacturing } \\
\text { - Recycling }\end{array}$ & {$[44,45]$} \\
\hline
\end{tabular}

environmental regulations imposed by legislative bodies or pressure from other stakeholders, company attitude towards environment-related issues, or a company's demographics, among others. The model could also be further developed by adding weights to its rules to boost the role of certain recovery policies in the environments they are considered necessary in.

\section{References}

1. Georgiadis, P. and Vlachos, D. (2004). The Effect of Environmental Parameters on Product Recovery, European Journal of Operational Research, 157(2): 449-464.

2. Dubois, D. and Prade, H. (1980). Fuzzy Sets and Systems: Theory and Applications. Academic Press, New York.

3. Fine, C. (1996). Industry Clockspeed and Competency Chain Design: An introductory Essay. In: Proceedings of the 1996 Manufacturing and Service Operations Management Conference, Hanover, New Hampshire, Dartmouth College, June 24-25, pp. 140-144.

4. Fine, C. (1998). What Fruit Flies Teach us About Business. The Insights of Clock-speed, Clockspeed: Winning Industry Control in the Age of Temporary Advantage, Chapter 2, p. 17, Reading, MA: Perseus Books.

5. Blackburn, J.D., Guide, V.D.R., Souza, G.C. and Van Wassenhove, L.N. (2004). Reverse Supply Chains for Commercial Returns. California Management Review, 46(2): 6-22.

6. Geyer, R. and Jackson, T. (2004). Supply Loops and Their Constraints: The Industrial Ecology of Recycling and Reuse. California Management Review, 46(2): 55-73.

7. Guide, D. (2000). Production Planning and Control for Remanufacturing: Industry Practice and Research Needs, Journal of Operations Management, 18(4): 467-483.
8. Fernández, I. (2004). Reverse logistics implementation in manufacturing companies $P h D$ dissertation. University of Vaasa Finland. ISBN: 952-476-046-0.

9. Reinhardt, F. (2000). Sustainability and the Firm, Interfaces, 30(3): 26-41.

10. Stock, J. (1998). Development and Implementation of Reverse Logistics Programs, Oak Brook, IL: Council of Logistics Management.

11. Pohlen, T. and Farris, M. (1992). Reverse Logistics in Plastics Recycling, International Journal of Physical Distribution \& Logistics Management, 22(7): 35-47.

12. Lalonde, B.J. and Cooper, M. (1989). Partnerships in Providing Customers Service: A Third Party Perspective. Oak Brook, IL: Council of Logistics Management.

13. Biddle, D. (1993). Recycling for Profit: The New Green Business Frontier. Harvard Business Review, 71(6): $145-156$.

14. Thierry, M., Salomon, M., Nunnen, J. and Wassenhove, L. (1995). Strategic Issues in Product Recovery Management, California Management Review, 37(2): 114-135.

15. Ayres, R., Ferrer, G. and Van Leynseele, T. (1997). Ecoefficiency, Asset Recovery and Remanufacturing. European Management Journal, 15(5): 557-574.

16. Krikke, H., le Blanc, I. and van de Velde, S. (2004). Product Modularity and the Design of ClosedLoop Supply Chains. California Management Review, V46(2): 23-39.

17. Purohit, D. (1992). Exploring the Relationship Between the Markets for New and Used Durable Goods: the Case of Automobiles. Marketing Science, 11(2): 154-167.

18. Tan, A. and Kumar, A. (2003). Reverse Logistics Operations in the Asia-Pacific Region Conducted by Singapore Based Companies: an Empirical Study. Conradi Research Review, 2(1): 25-48. 
19. Kang, H.Y. and Schoenung, J.M. (2005). Electronic Waste Recycling: A Review of, US. Infrastructure and Technology Options, Resources, Conservation \& Recycling, 45(4): 368-400.

20. Blumberg, D.F. (1999). Strategic Examination of Reverse Logistics and Repair Service Requirements, Needs, Market Size, and Opportunities, Journal of Business Logistics, 20(2): 141-159.

21. Debo, L.G., Toktay, L.B. and Van Wassenhove, L.N. (2005). Market Segmentation and Product Technology Selection for Remanufacturable Products, Management Science, 51(8): 1193-1205.

22. Vietor, R.H.K. (1993). Xerox, Design for the Environment, Harvard Business School Case 794-022, Cambridge, MA Harvard University.

23. Fazel Zarandi, M.H., Türksen, I.B. and Saghiri, S. (2002). Supply Chain: Crisp and Fuzzy Aspects, International Journal Applied Mathematical Computing Science, 12(3): $423-435$.

24. Chen, C.T. and Huang, S.F. (2006). Order-Fulfillment Ability Analysis in the Supply-Chain System with Fuzzy Operation Times, International Journal of Production Economics. 101(1): 185-193.

25. Lin, C.W.R. and Chen, H.Y.S. (2004). A Fuzzy Strategic Alliance Selection Framework for Supply Chain Partnering Under Limited Evaluation Resources, Computers in Industry, 55(2): 159-179.

26. Xie, Y., Petrovic, D. and Burnham, K. (2006). A Heuristic Procedure for the Two-Level Control of Serial Supply Chains Under Fuzzy Customer Demand. International Journal of Production Economics, 102(1): 37-70.

27. Wang, J. and Shu, Y.F. (2005). Fuzzy Decision Modeling for Supply Chain Management, Fuzzy Sets and Systems, 150(1): 107-127.

28. Giannoccaro, I., Pontrandolfo, P. and Scozzi, B. (2003). A Fuzzy Echelon Approach for Inventory Management in Supply Chains, European Journal of Operational Research, 149(1): 185-196.

29. Petrovic, D., Roy, R. and Petrovic, R. (1999). Supply Chain Modelling Using Fuzzy Sets, International Journal of Production Economics, 59(1-3): 43-453.

30. Petrovic, D. (2001). Simulation of Supply Chain Behaviour and Performance in an Uncertain Environment, International Journal of Production Economics, 71(1): 429-438.

31. Sheu, J. (2004). A Hybrid Fuzzy-Based Approach for Identifying Global Logistic Strategies, Transportation Research Part E, 40: 39-61.

32. Zadeh, L.A. (1983). The Role of Fuzzy Logic in the Management of Uncertainty in Expert Systems, Fuzzy Sets and Systems, 11(3): 199-227.

33. Lootsma, F. (1997). Fuzzy Logic for Planning and DecisionMaking. Kluwer, Dordrecht.

34. Driankov, D., Hellendoorn, H. and Reinfrank, M. (1996). An Introduction to Fuzzy Control. 2nd edn, Berlínl: Springer-Verlag.

35. Chen, C.B. and Klein, C.M. (1997). An Efficient Approach to Solving Fuzzy MADM Problems, Fuzzy Sets and Systems, 88: 51-67.
36. Mamdani, E.H. and Gains, B.R. (1981). Fuzzy Reasoning and its Applications. New York. Academic Press.

37. Cox, E. (1994). The Fuzzy Systems Handbook. Academic Press, Inc. London.

38. Ashayeri, J., Heuts, R. and Jansen, A. (1999). Inventory Management of Repairable Service Parts for Personal Computers: A Case Study, International Journal of Operations \& Production Management, 16(12): 74-97.

39. Ferrer, G. (1997). The Economics of Personal Computer Remanufacturing, Resources, Conservation and Recycling, 21(2): 79-108.

40. Krikke, H., Harten, A. and Schuur, P.C. (1999a). Business Case Roteb: Recovery Strategies for Monitors, Computers and Industrial Engineering, 36(4): 739-757.

41. Tan, A.W.K., Yu, W.S. and Kumar, A. (2003). Improving the Performance of a Computer Company in Supporting its Reverse Logistics Operations in the Asia-Pacific Region, International Journal of Physical Distribution \& Logistics Management, 33(1): 59-74.

42. Jayaraman, V., Patterson, R.A. and Rolland, E. (2003). The Design of Reverse Distribution Networks: Models and Solution Procedures, European Journal of Operational Research, 150(1): 128-149.

43. Krikke, H.R., Harten, A. and Schuur, P.C. (1999b). Business Case oce: Reverse Logistic Network Re-Design for Copiers, OR Spektrum, 34(3): 381-409.

44. Bellmann, K. and Kahre, A. (2000). Economic Issues in Recycling End-of-Pipe Vehicles, Technovation, 20(12): 677-690.

45. Sunthonpagasit, N. and Duffey, M.R. (2004). Scrap Tires to Crumb Rubber: Feasibility Analysis for Processing Facilities, Resources, Conservation and Recycling, 40: 281-299.

46. de Brito, M.P. (2004). Managing Reverse Logistics or Reversing Logistics Management. Thesis. https://ep.eur.nl/ bitstream/1765/1132/1/EPS-2004-035IS+9058920585+DEBRITO.pdf

47. Ferrer, G. and Ayres, R.U. (2000). The Impact of Remanufacturing in the Economy, Ecological Economics, 32(3): 413-429.

48. Fleischmann, M. (2000). Quantitative Models for Reverse Logistics, PhD Thesis, Erasmus University Rotterdam, Rotterdam, The Netherlands.

49. Hofstede, G. (1994). He, She, and (S)he, Cultures and Organizations, Software of the Mind. Intercultural Cooperation and its Importance for Survival, Chapter 4, p. 115, Glasgow: Harper Collins Publishers. ISBN: 0006377408 .

50. Johnson, M. and Wang, M. (1995). Planning Product Disassembly for Material Recovery Opportunities, International Journal of Production Research, 33(1): 3119-3142.

51. Penev, K.D. and de Ron, A.J. (1996). Determination of a Disassembly Strategy, International Journal of Production Research, 34(2): 495-506.

52. Realff, M.J., Ammons, J.C. and Newton, D.J. (2004). Robust Reverse Production System Design for Carpet Recycling, IIE Transactions, 36(8): 767-776. 


\section{Isabel Fernández}

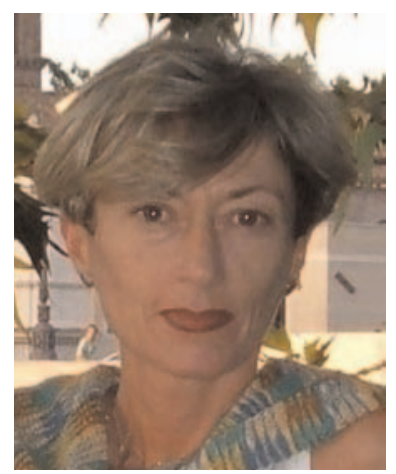

Isabel Fernández has been working for the University of Oviedo. (Spain), Department of Business Administration, since 1997 up to now, mainly teaching Logistics and Production Organization, except for over one year, when she worked as a Senior Lecturer in the Faculty of Management in the University of Vaasa (Finland), giving courses on the same topics. She has an MBA and her PhD is on Reverse Logistics, a field in which she is actually devoting her current research, along with other areas of interests, such as, Supply Chain Management or Costs Analysis. During her academic life she has also participated in several projects focused on Logistics and Quality, and has attended over 50 national and international conferences. Apart from her academic life, she has working experience in the Basque Government, in a private company and other teaching institutions, both in Spain and England.

\section{Javier Puente}

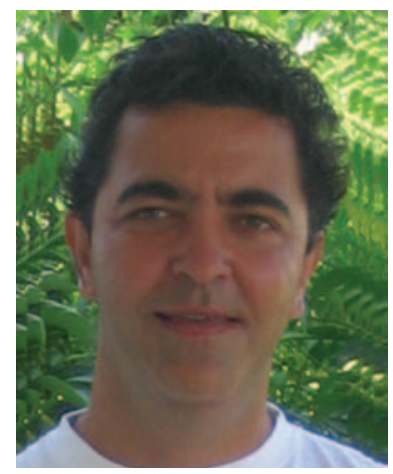

Javier Puente belongs to the Permanent Research Staff at the University of Oviedo (Spain) since 2005 in the Business Administration Department. He received his $\mathrm{PhD}$ in Industrial Engineering from the University of Oviedo in January 2002. His research interests include artificial intelligence applications to business management, specifically to classification, optimization and decision making problems. His research has appeared in many prestigious journals such as 'Artificial Intelligence for Engineering Design', 'Analysis and Manufacturing', 'International Journal of Foundations of Computer Science', 'International Journal of Quality and Reliability Management', 'Applied Artificial Intelligence', 'Integrated Manufacturing Systems', 'International Journal of Production Economics' 'International Journal of Healthcare Technology and Management', 'Artificial Intelligence for Engineering Design', 'Analysis and Manufacturing', and in several international conferences.

\section{Nazario García}

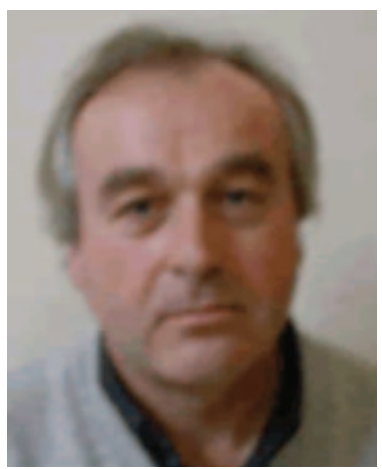

Nazario García (PhD, MBA) is Senior lecturer and researcher of the University of Oviedo (Spain) since 1998, affiliated to the Business Administration Department. Former Pur-chasing manager at a military company, where he worked for 24 years. Also in charge of Supplier evaluation and internal audits. Counselor in rural hotel and industrial waste treatment plant implementation. Several national and international publications. Participation in six research projects and national and international scientific conferences. Visiting lecturer at the University of El Salvador and La Habana (Cuba). Seminars and courses on Marketing, Logistics, Purchasing, Production and Quality. Currently he is Secretary of Asturian Logistics Foundation.

\section{Alberto Gomez}

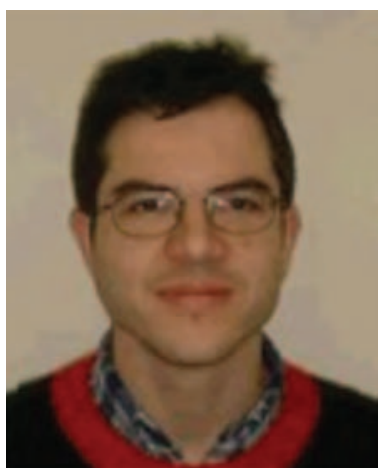

Alberto Gomez belongs to the Permanent Research Staff at the University of Oviedo (Spain) since 2006 in the Business Administration Department. He received his $\mathrm{PhD}$ in Industrial Engineering from the University of Oviedo in November 2001. His research interests include artificial intelligence applications to business management, specifically to classification, optimization and decision making problems. His research has appeared in many prestigious journals such as 'Journal of the Operational Research Society'. 'The Practical Handbook of Genetic Algorithms: Applications'. 'Artificial Intelligence for Engineering Design, Analysis and Manufacturing'. 'International Journal of Foundations of Computer Science'. 'European Journal of Operational Research'. 'International Journal of production economics'. 'Int. Journal of Healthcare Technology and Management'. 'Artificial Intelligence for Engineering Design, Analysis and Manufacturing'. 'Strojni Vestnik Journal of Mechanical Engineering' and in several international conferences. 